
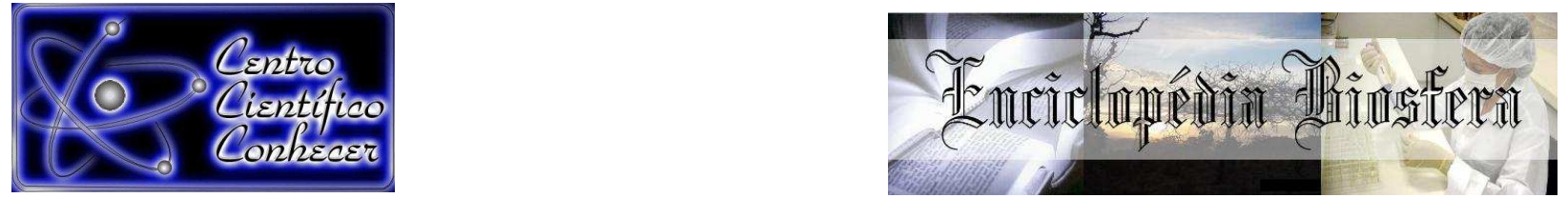

\title{
O USO DOS SMARTPHONES NO COTIDIANO DOS JOVENS E OS PRINCIPAIS APLICATIVOS UTILIZADOS PARA AUXILIAR NOS ESTUDOS - UM ESTUDO DE CASO
}

Chelry Fernanda Alves de Jesus ${ }^{1^{*}}$; Alexandre Martins Bueno Ferreira ${ }^{2}$; Mirelle Ferreira Alves ${ }^{3}$; Edney Marques Silva ${ }^{4}$; Nyuara Araújo da Silva Mesquita ${ }^{5}$.

1. Mestre em Química, Profa do Instituto Federal de Educação, Ciência e Tecnologias (IFG)- Câmpus Uruaçu. Membro do Núcleo de Pesquisa Ensino de Ciências e Educação Matemática (ENCIEM-IFG)(chelryquimica@yahoo.com.br).

2. Mestre em Engenharia de Computação, Professor do IFG-Uruaçu. Membro do ENCIEM-IFG.

3. Iniciação Científica, cursando Análise de Desenvolvimento de Sistema (IFGUruaçu)

4. Iniciação Científica, cursando Licenciatura em Química (IFG-Uruaçu) 5. Dra em Química, Profa Universidade Federal de Goiás (UFG), Coordenadora do Laboratório de Laboratório de Educação Química e Atividades Lúdicas (LequalUFG).

Recebido em: 08/04/2017 - Aprovado em: 10/06/2017 - Publicado em: 20/06/2017 DOI: 10.18677/EnciBio_2017A140

\begin{abstract}
RESUMO
É notório nos dias atuais o uso dos smartphones pelos jovens, dessa maneira procurou-se investigar quais as principais atividades que os jovens utilizam em seus aparelhos, na busca de desvelar se os jovens utilizam os celulares apenas para acessar as redes sociais ou se há outro direcionamento como o uso de aplicativos educacionais disponíveis em rede. Nessa perspectiva, foram aplicados questionários a estudantes dos cursos técnicos integrados de um Campus do Instituto Federal em Goiás e, a partir disso, fez-se um recorte dos principais softwares citados. Realizouse uma análise dessas ferramentas, considerando as perspectivas pedagógicas e as configurações técnicas disponibilizadas aos usuários. Dentre os principais aplicativos utilizados pelos jovens para fins educacionais citados foi o Google, Duolingo, YouTube, Geekie Games e calculadora. O uso desses aplicativos não é feito na maioria com a orientação pedagógica, sendo algo a ser trabalhado na perspectiva de melhor direcionamento do uso dessas ferramentas no âmbito educacional e a análise quanto à proposta pedagógica que podem oferecer.
\end{abstract}

PALAVRAS-CHAVE: aplicativos, celular, educação

\section{THE USE OF SMARTPHONES IN THE MIDDLE OF YOUNG PEOPLE AND THE MAIN APPLICATIONS USED TO HELP IN THE STUDIES - A CASE STUDY}

\footnotetext{
ABSTRACT

It is notorious nowadays the use of smartphones by young people, in this way we sought to investigate what the main activities that young people use in their devices, in the search of unveiling if young people use their cell phones only to access social ENCICLOPÉDIA BIOSFERA, Centro Científico Conhecer - Goiânia, v.14 n.25; p.1685 2017
} 
networks or if there is another Such as the use of educational applications available on the network. From this perspective, questionnaires were applied to students of the integrated technical courses of a Campus of the Federal Institute in Goiás and, from this, a cut of the main softwares mentioned was made. An analysis of these tools was carried out, considering the pedagogical perspectives and the technical configurations made available to the users. Among the main applications used by young people for educational purposes cited was Google, Duoling, Youtube, Geekie Games and calculator. The use of these applications is not done in the majority with the pedagogical orientation, being something to be worked on in the perspective of better targeting of the use of these tools in the educational scope and the analysis regarding the pedagogical proposal that they can offer.

KEYWORDS: applications, cellular, education

\section{INTRODUÇÃO}

É comum o uso dos celulares em todos os ambientes. Desde o início da sua comercialização no Brasil, na década de 90, os aparelhos celulares passaram por diversos avanços. O uso da internet nestes aparelhos configurou-os à versão smartphone, trazendo acesso a várias funcionalidades desde entretenimento, comunicação, localização e mídias. Atualmente, os celulares também têm disponibilizado algumas possibilidades educacionais a partir do uso de alguns aplicativos (app) (VÁSQUEZ-CANO \& SEVILLANO, 2015).

O uso do smartphones pelos jovens é algo habitual e estes os utilizam em qualquer ambiente, até na escola, lugar onde costuma ser proibido o uso. Isto pode ser observado a partir de resultados de pesquisas (BATISTA \& BARCELOS, 2013). De acordo com RIZZINI et al., (2005), em estudo com adolescentes brasileiros sobre mídia e novas tecnologias, os jovens conhecem e se adaptam rapidamente às tecnologias de informação e comunicação. O telefone celular conforme a referida pesquisa, realizada há cerca de uma década, tinha uma utilização por parte de $73 \%$ dos jovens entrevistados e $45,1 \%$ destes dedicavam mais tempo a este equipamento, superando, inclusive, o uso de videogames. Vale ressaltar que os pesquisadores apontam que os celulares eram mais utilizados nos países de primeiro mundo nessa época, no Brasil, esta ferramenta ainda estava ganhando espaço. Após cerca de uma década nota-se um cenário de mais adeptos e, ao mesmo tempo, conectados o tempo todo. Desta forma, o celular é muito mais que um aparelho utilizado para falar e escutar para os jovens, conforme aponta NICOLACI-DA-COSTA (2004):

Diante da liberdade, da autonomia e da privacidade precoces (por padrões tradicionais), que a telefonia celular lhes outorgou, [...] não é de espantar esses jovens vejam seus celulares como indispensáveis para as suas vidas (não custa lembrar que alguns chegam a falar deles como companheiros ou amigos). Por isso se desesperam quando, por algum acidente, não estão de posse do seu. Admitem depender dos celulares para subsidiar seu nomadismo e manter contato com o mundo fluido em que vivem. Sem eles, perdem o acesso imediato à sua rede social. $\mathrm{Na}$ ausência desse acesso, sentem-se excluídos do convívio de seus amigos, parentes, namorados, etc. e enfrentam uma nova forma de solidão (NICOLACI-DA-COSTA, 2004, p. 172). 
Dessa forma, estes aparelhos passaram a se configurar como uma espécie de bem simbólico, produtores de sentido, que suprem as expectativas da geração da internet e atuam nas práticas de socialização, compartilhamento de experiências e até mesmo de afirmação dos sujeitos e contexto em que vivem (LASH, 2014).

Nesse sentido, infere-se que esses equipamentos que têm outras funções além da comunicação, podem estar se constituindo como uma espécie de bem cultural e histórico enquanto componentes da sociedade. Segundo LEVY (2010), a sociedade está inserida numa Cibercultura, considerando-se que a comunicação já existia anteriormente com a escrita e a fala, mas a tecnologia trouxe a possibilidade do compartilhamento das informações ultrapassando limites de espaço e tempo, isso tudo conectado por instrumentos eletrônicos. Nesse cenário, o celular passou a ser um objeto muito mais que utilitário, passando a ser um objeto pessoal com significados sociais.

Bento \& Cavalcante (2013) defendem que os smartphones vêm sendo pouco utilizados nas escolas diante da gama de possibilidades que estes aparelhos oferecem, e isto vem causando alguns problemas relacionados à disciplina, concentração e participação. O que levou até alguns Estados do Brasil, dentre eles Goiás, a proibirem o uso do celular em sala de aula, gerando debates em torno do uso dessas tecnologias de informação e comunicação na educação (GOIÁS, 2010). Então, levando em consideração o uso dos celulares na escola pelos estudantes, a pesquisa tem como objetivo investigar quais os aplicativos disponíveis na internet que os jovens utilizam para auxiliar em seus estudos seja na sala de aula ou em casa. Além disso, pretende analisar os principais aplicativos citados pelos estudantes, considerando as questões pedagógicas proporcionadas por estes softwares.

\section{MATERIAL E MÉTODOS}

A pesquisa configura-se como um estudo de caso, pois o foco do estudo encontra-se bem delimitado e se destaca por se constituir em um recorte dentro de um contexto mais amplo, estando o interesse investigativo incidindo em um recorte particular que mostra evidências e semelhanças com outros casos ou situações (LUDKE \& ANDRÉ, 1986). A investigação foi realizada com 270 estudantes dos cursos técnicos integrados de Química, Informática e Edificações do IFG, Câmpus Uruaçu, do primeiro ao terceiro ano, no período de 16 a 20 maio de 2016, com a devida autorização da direção do Campus e o consentimento dos alunos para participar da pesquisa de forma voluntária, não obrigatória e sem prejuízos ao participante. Foram obtidos 152 questionários respondidos.

O modelo de questionário aplicado utilizou perguntas abertas quanto fechadas (anexo I), relacionadas às principais funções utilizadas em seus smartphones, o tipo de aparelho que utilizam, a importância dos aparelhos seja no seu dia-a-dia ou no auxílio às atividades escolares, focando em perguntas sobre 0 uso e a funcionalidade dos aparelhos em suas vidas.

Após a tabulação das respostas obtidas, foram classificadas as principais atividades utilizadas pelos estudantes nos aparelhos móveis e os principais app usados para fins educacionais. A partir dos aplicativos educacionais citados, foi realizada uma pesquisa sobre as configurações de tais softwares, considerando-se uma perspectiva pedagógica desses app e as possíveis contribuições no contexto escolar. 


\section{RESULTADOS E DISCUSSÃO}

\section{UTILIZAÇÃO DO CELULAR NO COTIDIANO}

No momento em que os questionários foram distribuídos apenas quatro alunos das nove turmas não tinham celular. Dentre os aparelhos utilizados pelos entrevistados os mais comuns foram: Motorola Moto G 2º Geração e o Sansung Galaxy Gran Duos, celulares com recursos de hardware medianos, que conseguem executar funções básicas e aplicativos de médio e leve porte, como os das redes sociais. Entre as principais atividades desenvolvidas nos dispositivos pelos entrevistados estão: acessar a internet, redes sociais, ouvir músicas e o uso de aplicativos para variados fins.

A Tabela 1 evidencia os resultados dos questionários respondidos pelos estudantes. Conforme os dados obtidos, frequentemente os jovens utilizam mais os aparelhos para acessar a internet e as redes sociais. Outras atividades que se destacaram foram: tirar foto e ouvir música. Para atender e fazer ligações às vezes utilizam e muito pouco para enviar mensagem sms e localizar endereço.

TABELA 1. Aplicabilidade do uso do celular pelos jovens estudantes do IF campus Uruaçu

\begin{tabular}{|l|c|c|c|c|}
\hline & $\begin{array}{l}\text { Nunca } \\
\text { usei }\end{array}$ & $\begin{array}{l}\text { Muito } \\
\text { pouco }\end{array}$ & $\begin{array}{l}\text { Às } \\
\text { vezes }\end{array}$ & Frequentemente \\
\hline Atender e fazer ligações & $2 \%$ & $21 \%$ & $35 \%$ & $41 \%$ \\
\hline $\begin{array}{l}\text { Enviar mensagem via } \\
\text { sms }\end{array}$ & $19 \%$ & $54 \%$ & $16 \%$ & $12 \%$ \\
\hline Tirar foto & $1 \%$ & $16 \%$ & $18 \%$ & $65 \%$ \\
\hline Ouvir música & $2 \%$ & $4 \%$ & $16 \%$ & $78 \%$ \\
\hline Acessar redes socias & $1 \%$ & $2 \%$ & $9 \%$ & $87 \%$ \\
\hline Acessar a internet & $1 \%$ & $2 \%$ & $5 \%$ & $93 \%$ \\
\hline Jogar & $7 \%$ & $32 \%$ & $30 \%$ & $31 \%$ \\
\hline Localizar endereços & $17 \%$ & $43 \%$ & $29 \%$ & $11 \%$ \\
\hline Assistir filmes & $21 \%$ & $25 \%$ & $32 \%$ & $21 \%$ \\
\hline Usar aplicativos & $2 \%$ & $2 \%$ & $14 \%$ & $82 \%$ \\
\hline
\end{tabular}

O fato de utilizarem a internet frequentemente está associado à funcionalidade que a conexão permite. Um dos aplicativos mais acessados hoje é o Whatsapp, por possibilitar trocas de mensagens instantâneas, envio de vídeos, áudio e ligações, desde que os usuários estejam conectados à internet. Conseqüentemente isso pode levar à diminuição do envio de mensagem via sms, porque são cobradas pelas operadoras, assim como as ligações. O Facebook 
também é muito acessado, usado como uma forma de socialização e interação com o meio, possibilitando acompanhar redes de amigos e páginas de interesse.

As ligações são mais frequentes para os parentes, sendo usado mais pelos familiares como acompanhamento das atividades dos jovens no dia-a-dia. Essa perspectiva corrobora os resultados apresentados por PONCIANO \& FÉRESCARNEIRO (2014), pois uma pesquisa, realizada com as mães de jovens de 14 a 26 anos, mostrou que o celular é permitido pelos pais como meio de monitoramento das atividades dos filhos, associado à sensação de segurança, mas que ao mesmo tempo é uma espécie de controle a distância.

Conforme os resultados da presente pesquisa, foram observados que os jovens estão inseridos num contexto social e cultural no qual os smartphones são mais que um objeto de comunicação, passando a ser acessibilidade, interação com o meio, aceitação em grupos e forma de expressões, ferramenta de entretenimento e auxílio nos estudos.

\section{IMPORTÂNCIA DO CELULAR PARA OS JOVENS}

Os alunos foram questionados também quanto à importância do celular para eles. Por se tratar de uma pergunta aberta, foi feita a organização das respostas a partir de quatro categorias: comunicação, entretenimento, acesso à informação e auxílio nos estudos. De acordo com as respostas, a importância do celular é direcionada mais à comunicação, como forma de falar com os pais e amigos, seja por meio de ligações ou mensagens em redes sociais. Algumas das respostas dos alunos relacionados a essa categoria foram:

Pois ele serve para comunicar-me com meus pais. (Estudante 1)

O celular é importante pois ajuda no dia-a-dia como ligações para os pais, mandar mensagens...conversar com amigos. (Estudante 2)

Os alunos não entraram em detalhes em suas respostas quanto às redes sociais utilizadas para a comunicação, mas em outras pesquisas foi evidenciado 0 uso do Whastapp, Facebook e Instagram como ferramentas atuais de comunicação mais utilizados (ALBACH, 2014). A importância do entretenimento foi muito comentada pelos entrevistados, mas não tanto quanto a comunicação, sendo considerada mais como uma forma de distração, diversão em atividades tais como ouvir música, jogar, tirar fotos e acessar redes sociais:

Por que consigo fazer muitas coisas nele, pesquisas, consigo me distrair, passar meu tempo. (Estudante 3)

Posso ter momento de lazer pelo celular. (Estudante 4)

Porque ele faz com que fiquemos conectados ao mundo inteiro, por dentro de tudo que é tecnológico e nos atende a muitas necessidades como ouvir músicas. (Estudante 5)

Tirar fotos para lembranças. (Estudante 6)

E outra importância categorizada na pesquisa foi o acesso às informações de maneira geral:

Porque consigo ter acesso a informação em qualquer lugar que eu esteja. (Estudante 7) 
Os entrevistados não citaram o tipo de informações as quais recorrem na internet, e nem foram entrevistados para aprofundar no assunto, mas conforme ALBACH (2014) buscar informações também está vinculado a redes sociais e sites tais como os blogs, é uma espécie de busca corriqueira do cotidiano de redes de amigos e informações da mídia e moda. Quanto ao uso vinculado aos estudos, muitos consideram importante:

Porque ele pode me auxiliar tanto nos estudos, quanto para facilitar a comunicação com amigos e família. (Estudante 9)

Tenho suporte nos estudos. (Estudante 10)

Então, percebeu-se pelos dados obtidos que o celular/smartphones também é adotado pelos jovens para estudar, embora ainda seja proibido o uso em sala de aula. Dentre as justificativas da proibição estão: dificuldade de concentração por parte dos alunos durante a aula, despreparo dos estudantes em não perceber a relação didática do uso do celular, as dificuldades operacionais da tecnologia, acesso limitado à tecnologia por parte de alguns alunos e a dificuldade de controle da dimensão que o uso pode causar. Sendo assim são muitos receios e medos ao se tratar do uso do celular em sala de aula, mas aos poucos esta ferramenta vem conquistando espaços e aplicabilidade didática, alguns professores utilizam a tecnologia, seja como ferramenta de busca, utilização de fotografias, vídeos e calculadora (MARTIN \&ERTZBERGER, 2013). Importante ressaltar que desde a implantação das reformas curriculares na década de 1990 no Brasil, há uma orientação nos documentos que balizam a educação nacional em termos de que as tecnologias se configurem como um dos eixos formativos da educação básica (BRASIL, 1996). Embora haja diversas questões contraditórias envolvidas nessas orientações, tais como a formação para o mercado de trabalho ou para o mercado consumidor, a escola não pode manter a margem da realidade do alcance das tecnologias na vida dos jovens.

Assim pode-se inferir que o uso das tecnologias não é instigado no ambiente escolar, mas que os jovens de certa maneira apropriam-se de alguns aplicativos para as atividades acadêmicas de maneira autônoma e sem mediação, considerando-se que essas tecnologias fazem parte do cotidiano da juventude, tendo como principal elemento representativo o celular, que se tornou objeto pessoal de utilidade das suas atividades. Contraditoriamente, estão imersos em um meio cultural educacional com formas pré-estabelecidas e sistemas rígidos de avaliação, sendo assim buscam o celular como uma ferramenta auxiliadora, o que não necessariamente contribui para o desenvolvimento da aprendizagem quando analisa os principais aplicativos utilizados por eles para este fim.

\section{APLICATIVOS UTILIZADOS PARA AUXILIAR NOS ESTUDOS}

Os aplicativos mais utilizados pelos estudantes para auxiliar nos estudos de acordo com os dados da pesquisa estão apresentados na Figura 1 e são listados a seguir: os aplicativos para ensino de línguas, como representante principal o Duolingo; as plataformas de busca na Web, sendo a mais comum o Google; as calculadoras; a plataforma de upload e visualização de vídeos como o YouTube; e, 
por último, os aplicativos e sites de auxílio a estudos para vestibulares e Enem, sendo o mais comum o Geekie Games.

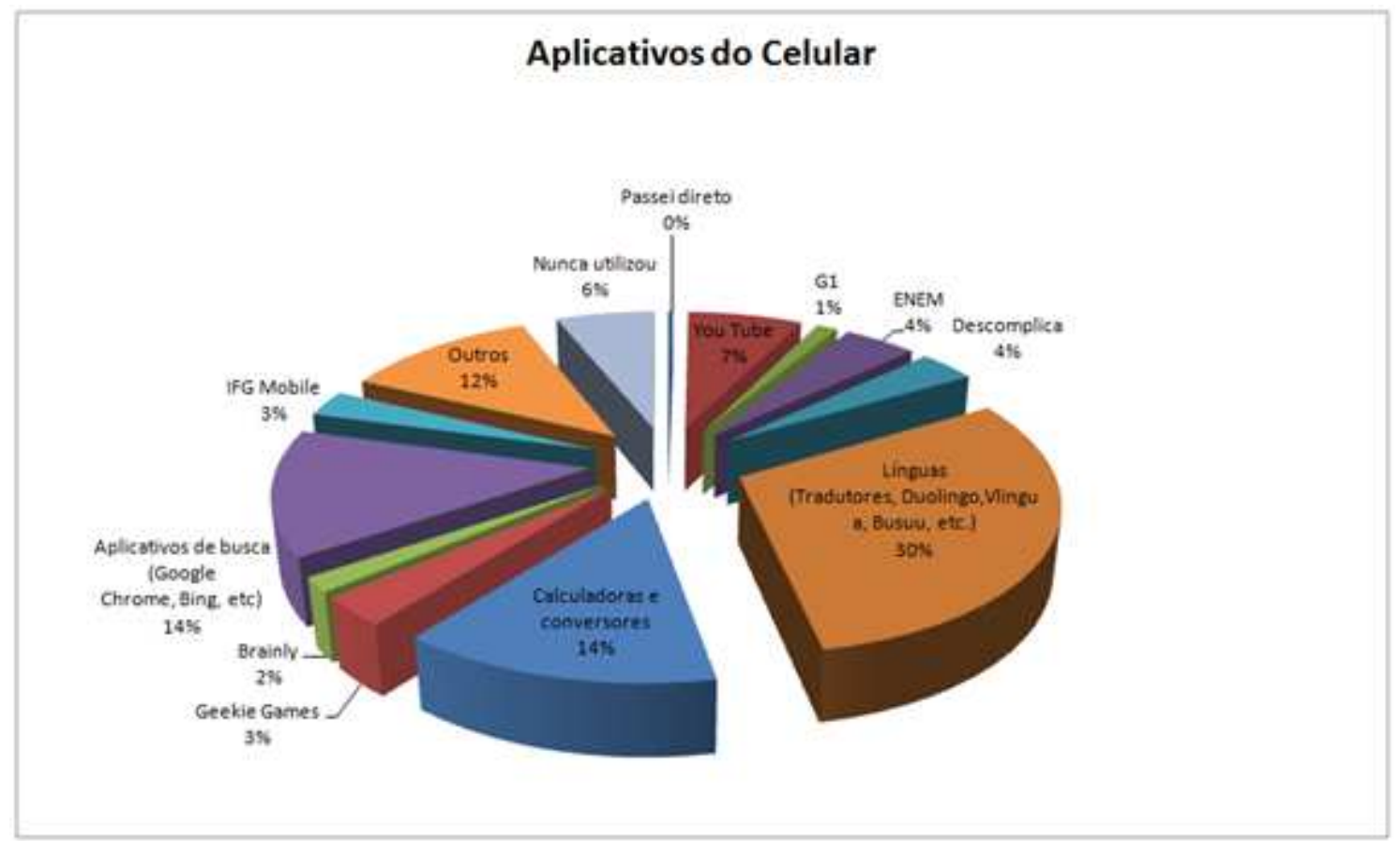

FIGURA 1. Principais aplicativos utilizados pelos estudantes do IFG de Uruaçu. Fonte: autores

A seguir, há uma caracterização dos aplicativos mais citados bem como uma análise das possibilidades didáticas destes aplicativos no âmbito escolar.

\section{Aplicativo Duolingo}

O Duolingo é um aplicativo encontrado na versão gratuita na rede para aprendizado de línguas, utilizado por mais de 40 milhões de usuários. Este aplicativo é capaz de ensinar uma série de idiomas, sendo os mais populares o Inglês, o Espanhol, o Francês e o Alemão. Neste, o ensino do idioma é organizado em pequenas fases, fazendo com que o aprendiz se sinta dentro de um jogo. Cada fase ensina uma parte de relevância do idioma, como verbos, artigos e o conteúdo associado a temas como meio ambiente, família, saudações, etc. Uma fase é composta por uma série de lições, que ensinam o aprendiz a ler, escrever, falar e compreender o idioma selecionado (VON AHN, 2013). Em pesquisa realizada por NEULS (2015) utilizando o Duolingo em sala de aula, os resultados mostraram que os jovens ficaram motivados ao usarem o aplicativo e a aula tornou-se "mais significativa" no sentido que os jovens aprenderam em sua maior parte palavras novas, cerca de 10 palavras.

O aplicativo funciona como um jogo, em que o usuário trabalha tanto a tradução, quanto à escrita e a fala. Baseado no ensino por estímulo e resposta, o estudante só passa para a próxima questão se acertar a anterior, caso erre volta para a mesma questão, o erro então é evidenciado para estimular o acerto. Dessa forma, a proposta do jogo trabalha com memorização de palavras em outras línguas. Segundo NEULS (2015), ao discutir a dinâmica do aplicativo: 
Usuários ganham "pontos habilidades" ao aprender conceitos sobre a linguagem (...). Pode se obter até 14 pontos por lição, com um ponto reduzido a cada erro cometido (...). O Duolingo também inclui uma opção de praticar com cronômetro. São dados 30 segundos para responder 20 questões. Se as questões forem feitas dentro do tempo, o usuário ganha 20 pontos (NEULS, 2015, p. 27).

Percebe-se que o software em questão não trata de maneira contextualizada os conteúdos e traz uma abordagem na perspectiva tradicional de ensino, a partir da lógica do conhecimento sistematizado e ênfase no estímulo resposta, uma visão que pode ser classificada como Skinneriana, considerando o método como foi elaborado com perguntas e vinculação de avanço nas próximas etapas condicionadas ao acerto. Dessa forma, o software vai de contramão das tendências educacionais das disciplinas escolares, as quais versam para uma abordagem mais do sentido e significado ao sujeito e não meramente memorística, como o construtivismo (MATUI, 1995) e a educação pela pesquisa (DEMO, 2011).

A motivação do uso do software de aprendizagem da língua inglesa é uma forma de inserção social, apropriação de formas culturais que possibilitam o sujeito a comunicação com o mundo e, por se tratar de inglês a língua mais difundida na parte econômica e apropriada historicamente em diversos países, é notável despertar certo interesse dos estudantes em aprender a língua e a buscarem aplicativos que possibilitem aprender várias línguas, embora não seja muito difundido seu uso em na sala de aula por parte dos professores (MOTA et al, 2017).

\section{Aplicativo Geekie Games}

O Geekie Games é uma plataforma reconhecida pelo Ministério da Educação (MEC, 2011) e que tem por objetivo traçar planos de estudos individuais para o Exame Nacional do Ensino Médio (ENEM) de acordo com as necessidades de cada aluno. Hoje está vinculada a Hora do Enem, um programa nacional lançado pelo MEC 2016. Apresenta uma gama de possibilidades ao estudante, como programa de TV, simulados online, aplicativos para celular e outros. $O$ plano gratuito inclui mais de 600 aulas e simulados com notas do ENEM, diferindo das versões pagas por não incluir um "plano de estudo inteligente" e "desempenho por assunto Enem", o que por sua vez não compromete o desempenho do estudante. A plataforma está disponível on line no site http://horadoenem.mec.gov.br/.

Claudio Sassaki e Eduardo Bontempo foram os criadores do Geekie Games em 2011, inspirados no Khan Academy, que é uma plataforma americana que disponibiliza os conteúdos gratuitos da internet, sendo assim propuseram uma versão diferenciada no sentido de ser uma proposta personalizada como uma plataforma online para preparação do Enem. Nesse sentido, o Geekie trabalha com processo de avaliação da Teoria do Item Resposta (TRI), o qual é o mesmo processo avaliativo que baliza as correções do ENEM. Então a proposta dos criadores foi fazer uma plataforma virtual de banco de exercícios que possibilitasse ao aluno testar os seus conhecimento (GEEKIE GAMES, 2017).

Conforme aponta LEAL (2014), a plataforma de certa maneira apresenta-se atrativa no sentido de oferecer possibilidade de aprendizado pelo uso e mediação das tecnologias, mas ao analisar detalhadamente a proposta, o referido autor percebeu que: 
Entretanto, quando observada mais atentamente, verificou-se que, apesar da mediação tecnológica, não há um esforço pelo desenvolvimento de habilidades extradisciplinares, e sim, uma corroboração de técnicas e sistemas de avaliação tradicionais. Tampouco apresenta espaços e tarefas que tragam a mecânica, as estratégias e os pensamentos cultivados na elaboração dos games, cuja finalidade é motivar os indivíduos à ação, auxiliar na solução de problemas e promover aprendizagens. No fim, a plataforma instiga a resolução de problemas isolados e a consolidação do conhecimento formal, cujas capacidades exigidas visam muito mais a memorização do que a compreensão global (LEAL, 2014, p.27).

Dessa forma, nota-se que, embora a plataforma traga uma gama de possibilidades como vídeos-aulas, textos e esquemas, faz-se necessário a mediação por parte do professor para um melhor aproveitamento da plataforma considerando as possibilidades de estímulo à aprendizagem de forma dinâmica e interativa.

\section{Aplicativo calculadora}

As calculadoras são ferramentas comuns em todos os celulares modernos e os seus sistemas operacionais já são equipados com calculadoras-padrão. Alguns modelos de celulares já vêm normalmente equipadas com duas versões, a primeira versão é uma calculadora padrão, que faz cálculos aritméticos básicos, enquanto a segunda versão trata-se de uma calculadora científica capaz de realizar cálculos complexos e que pode ser ativada de várias formas, variando de celular para celular (em alguns, basta virar a tela; em outros, é necessário acessar um menu específico). As calculadoras dos smartphones normalmente não exigem muita memória dos aparelhos por possuírem tamanho reduzido. Em geral, ocupam menos de $3 \mathrm{Mb}$ de espaço de armazenamento, interferindo pouco no funcionamento dos dispositivos. Estes aplicativos dificilmente apresentam erros e problemas, além de serem muito úteis e eficientes (JOBSTRAIBIZER, 2009).

O uso da calculadora na sala de aula é algo bastante questionado. Há opositores que dizem que o uso da calculadora tem efeitos negativos sobre o desenvolvimento da aprendizagem do aluno, podendo comprometer a capacidade de raciocínio lógico matemático. Em contrapartida, há os que defendem que o uso da calculadora traz vantagens como a estimulação à resolução de problemas, exige concentração na elaboração da estratégia para resolução do problema do que em cálculos (DA PONTE \&CEBOLA, 2008).

Apesar dessa discussão em torno do uso e do não uso, a utilização se intensificou com o celular, e, mesmo não sendo incentivado seu uso na sala de aula, os estudantes utilizam o aplicativo pela praticidade para resolver contas. Uma reflexão que precisa ser feita relaciona-se a propor estratégias para ensinar o aluno a usar a calculadora de maneira consciente, pois usar a calculadora para facilitar a resolução de problemas é um aspecto relacionado ao uso da ferramenta, o mais importante é que os alunos compreendam as operações que envolvam os cálculos e isso o aplicativo não proporciona. Então em sala de aula os alunos recorrem mais a calculadora pela dificuldade na operação matemática, nesse sentido, é preciso repensar $o$ uso da calculadora na sala de aula. É interessante refletir, pedagogicamente falando, sobre a contribuição da calculadora sob o ponto de vista cognitivo no contexto do processo de ensino aprendizagem (PONTE, 1995). 


\section{Aplicativo YouTube}

O YouTube é uma plataforma para compartilhamento de vídeos lançada no ano de 2005, possui uma interface de comunicação bem simples e intuitiva, permitindo com que os usuários realizem facilmente o envio (upload) e a visualização de vídeos. A plataforma possui, atualmente, centenas de milhões de vídeos hospedados e mais de um bilhão de usuários ativos, o que gera algo em torno de três bilhões de horas visualizadas dos vídeos por mês. A plataforma também funciona como uma ferramenta de marketing, onde os anunciantes podem divulgar seus produtos em banners e em anúncios, podendo estes ser inseridos antes, durante e após a visualização dos vídeos disponíveis (YOUTUBE, 2016; $\mathrm{HOSCH}, 2017)$.

A plataforma YouTube é utilizada para os mais diversos fins, tais como entretenimento e educação (JAFFAR, 2012). A área educacional se destaca, com conteúdo disponibilizado por milhares de universidades, institutos e escolas. Existem dezenas de milhões de vídeos com conteúdo instrucional disponibilizados, e acessados dezenas de bilhões de vezes (inclusive, milhares de cursos completos estão disponíveis na plataforma). Além disso, inúmeras ferramentas de ensino a distância hospedam seus vídeos na plataforma e fazem referências a eles em suas páginas de conteúdo (OLIVEIRA, 2013).

Por se tratar de uma plataforma que possibilita usuários participar tanto de forma passiva quanto ativa, apresenta dupla função. Essa dupla função pode ser entendida como propagador dos produtos da mídia comercial ou como propagador da cultura popular criada pelos usuários que desafia a mídia monopolizadora, mas que contribui para a exploração da mídia tradicional no aspecto de análise da cultura popular (BURGESS \& GREEN, 2009).

Os jovens, inseridos nessa cultura popular e midiática, acessam os vídeos como entretenimento, procurando assistir filmes e vídeos clipe de música. Em relação ao acesso como forma de busca de informações, costumam acessar vídeo aulas curtas, das quais muitas foram produzidas por escolas particulares como cursinhos preparatórios que utilizam a plataforma como um meio de marketing para suas empresas. As vídeoaulas disponibilizadas apresentam características de abordagem tradicional de ensino, baseando-se no modelo transmissão-recepção e priorizando esquemas memorísticos para facilitar a resolução de exercícios. O caráter dessas vídeoaulas de certa maneira serve mais como um suporte aos estudos, mas que não substitui a aula em si (MORÁN, 1995).

\section{Aplicativo Google}

O Google é a plataforma de buscas na web mais utilizada no Brasil atualmente. Este está vinculado a diversos outros serviços digitais. Quando um usuário cria ou possui uma conta no Google, automaticamente consegue acessar serviços como You Tube, o Google +, o Gmail, GoogleDocs e etc. O Google está disponível como site de busca e como um navegador de Internet (Google Chrome). O navegador é um aplicativo leve, com pouca utilização de memória dos dispositivos móveis, o que proporciona interface de fácil acesso, e, por isso, bastante utilizada. A plataforma é rápida, e em questão de décimos de segundos as possibilidades de sites que apresentam as palavras-chaves buscadas são apresentadas. Muitas pessoas se perguntam como a plataforma funciona, pois se esta indexa todos os sites da internet, como pode ser tão rápida. A resposta para estas perguntas está no Googlebot, um robô do Google, responsável por "varrer" a Internet fazendo uma 
espécie de cópia dos sites, em que cada cópia fica vinculada ao seu respectivo site. Quando algo é buscado na ferramenta de pesquisa, os conteúdos pesquisados são aqueles que o robô guardou, apresentando os links para os sites que mais se relacionaram com os termos pesquisados (VISE, 2007).

Embora haja facilidade no acesso às informações por meio de buscas via internet, há problemas relacionados à qualidade dessas informações, pois a plataforma não é programada para ser direcionada a conteúdos científicos apenas. É uma página de buscas em geral, é necessário proporcionar ao aluno uma melhor compreensão dos conteúdos trabalhados em sala de aula por meio da pesquisa, porque os alunos trazem uma bagagem de conhecimento arraigada no senso comum, "muitas vezes sem pesquisa prévia, método e teoria" (RAMOS, 2012).

Por conseguinte, a utilização destes aplicativos de buscas proporciona facilidades e agilidade ao acesso e busca por informações, entretanto se faz necessário que a escola trabalhe com questões do uso consciente dessas ferramentas, buscando levar os alunos a perceber criticamente as fontes confiáveis ou não. Segundo CARVALHO (2007), há uma falácia por parte dos jovens de que tudo que há na internet é bom e está certo, isso leva a uma discussão maior, porque os sites em sua maioria não são acompanhados por uma equipe especializada no assunto, poucos sites como os de revistas acadêmicas possuem um corpo editorial com avaliadores dos artigos publicados. Outro aspecto relevante nessa discussão de acesso refere-se às questões de plágio:

Muitos professores constatam plágios frequentes nos trabalhos e muitos deles não são por desonestidade dos alunos, é mesmo por ignorância. Aprender a analisar, a sintetizar e a reaplicar em diferentes contextos, torna-se imprescindível e pode ser, simultaneamente, uma forma de combater o plágio (CARVALHO, 2007, p. 30).

A partir desses aspectos citados, o papel da escola pode ser importante no sentido de discutir com os alunos páginas que sejam confiáveis em termos de informações apresentadas, como páginas de revistas científicas, por exemplo. Além disso, seria importante que a discussão sobre a necessidade de que, ao fazer um trabalho de pesquisa escolar, os estudantes apresentassem as fontes de onde tiram suas informações o que denotaria a preocupação com as questões referentes ao plágio no contexto escolar.

\section{CONCLUSÃO}

A pesquisa desvelou que o uso do celular pelos jovens não só direciona a comunicação e entretenimento, mas que estes utilizam aplicativos para auxiliar nos estudos, entretanto os processos de apropriação desses apps no campo educacional é mediado pela educação não formal e não por um direcionamento pedagógico formal, os estudantes utilizam os apps como uma apropriação cultural da internet sem de fato ter o discernimento para questionamentos das ferramentas. Os principais aplicativos acessados pelos jovens são reproduções de uma influência do ensino tradicional, fruto de desenvolvimento na maioria por parte de técnicos de informática não ligados a área de ensino.

A limitação por dos professores quanto à linguagem e programação computacional contribui para parte disto, outra questão é a dificuldade dos professores em lidar com essas tecnologias, pois tiveram que adaptar as TIC, ao ENCICLOPÉDIA BIOSFERA, Centro Científico Conhecer - Goiânia, v.14 n.25; p.1695 
contrário dos alunos que nascerem inseridos na cultura digital. Consequentemente, estas limitações passa a ser uma barreira entre a utilização dos celulares na sala de aula e com isso colabora para uso sem orientação dos jovens do celular ligado a fins educacionais. Frente a isso, torna-se importante a implantação dos projetos educacionais que inclua o celular como um instrumento pedagógico capaz de auxiliar no processo de ensino aprendizagem, de maneira a chamar o universo ao qual o sujeito está inserido e conectado.

Embora a tecnologia não seja a tábua de salvação da educação, porque sabemos que é um processo complexo permeado por esferas tanto a nível política, cultural, social e econômica. Mas educar com uso dos dispositivos móveis implica em compreender esse processo de desenvolvimento que os sujeitos fazer parte, é tentar aproximar as novas formas de comunicação no processo dialético de desenvolvimento do indivíduo.

\section{REFERÊNCIAS}

ALBACH, J. S. Os usos que os jovens fazem da internet: Relações com a escola. Revista Eletrônica de Educação, v. 8, n. 2, p. 138-159, 2014. Disponível em: < http://www.reveduc.ufscar.br/index.php/reveduc/article/view/739/330>. doi:1014244/19827199

BATISTA, S. C. F.; BARCELOS, G. T. Análise do uso do celular no contexto educacional. Renote, v. 11, n. 1, 2013.

BENTO, M. C. M.; CAVALCANTE, R. dos S. Tecnologias móveis em educação: o uso do celular em sala de aula. ECCOM, v.4, n.7, p.113-120, 2013.

BRASIL, L. D. B. Lei 9394/96-Lei de Diretrizes e Bases da Educação Nacional. 1996.

BURGESS, J.; GREEN, J. You Tube e a revolução digital. São Paulo: Aleph, 2009, p. 24.

CARVALHO, A. A. A. Rentabilizar a Internet no Ensino Básico e Secundário: dos recursos e ferramentas online aos LMS. Sísifo, Revista de Ciências da Educação. n. 3, p. 30, 2007.

DA PONTE, J. P.; CEBOLA, G. O uso da calculadora básica e científica no ensino da Matemática: uma questão ainda por resolver, 2008. Disponível em: <http://spiem.pt/DOCS/ATAS_ENCONTROS/2008/2008_05_JPPonte.pdf>, acessado 13 nov. 2016.

DEMO, P. Educar pela pesquisa. Autores Associados, 2011.

GOIÁS (Estado). Lei n. 16.999, de 10 de maio de 2010. Dispõe sobre proibição do uso celular na sala de aula em toda rede de ensino estadual. Diário Oficial do Estado de Goiás, Goiânia, 16 jun. 2010.

GEEKIE GAMES, Disponível em: <http://info.geekie.com.br/>, acessado 02 fev. 2017. 
HOSCH, W. L. Youtube. Encyclopaedia Britannica, 2017.

JAFFAR, A. A. YouTube: An emerging tool in anatomy education. Anatomical sciences education, v. 5 , n. 3, p. 158-164, 2012. Disponível em: < http://onlinelibrary.wiley.com/doi/10.1002/ase.1268/full>. doi: 10.1002/ase.1268

JOBSTRAIBIZER, F. Criação de aplicativos para celulares com Google Android. São Paulo: Digerati Books. 2009.

LASH, Scott. Formas tecnológicas de vida. Estudos de Sociología, v. 1, n. 8, p. 11 33, 2014.

LEAL, A. S. Educação 3.0 e Geekie Games. Trabalho de Conclusão de Curso. 2014, 30 f. (Especialiação)- Universidade de São Paulo Centro de Estudos Latino Americanos sobre cultura e comunicação, São Paulo, p.27, 2014.

LEVY, P. Cibercultura. Editora 34, 2010.

LUDKE, M.; ANDRÉ, M. E. Pesquisa em educação: abordagens qualitativas. 1986.

MARTIN, F.; ERTZBERGER, J. Here and now mobile learning: An experimental study on the use of mobile technology. Computers \& Education, v. 68 , p. $76-85$, 2013. Disponível em: <http://dx.doi.org/10.1016/j.compedu.2013.04.021>. doi: 10.1016/j.compedu.2013.04.021

MATUI, J. Construtivismo: teoria construtivista sócio-histórica aplicada ao ensino. Moderna, 1995.

MORÁN, J. M. O vídeo na sala de aula. Comunicação \& Educação, n. 2, p. 27-35, 1995. Disponível em: <http://dx.doi.org/10.11606/issn.2316-9125.v0i2p27-35>. DOI: 10.11606/issn.2316-9125.v0i2p27-35.

MOTA, B. C. C.; COELHO, C. R.; SILVA, V. M. C.; NETO, M. M. J. Duolingo: inovação do inglês na escola. Form@ re. Revista do Plano Nacional de Formação de Professores da Educação Básica/Universidade Federal do Piauí, v. 4, n. 1, 2017.

NEULS, D. E. O uso de softwares educacionais no Ensino da Língua Inglesa. Trabalho de Conclusão de Curso. 2015, 46 f. (Especialização)- Universidade Federal do Rio Grande do Sul, Tio Hugo-RS. 2015.

NICOLACI-DA-COSTA, A. M. Impactos psicológicos do uso de celulares: uma pesquisa exploratória com jovens brasileiros. Psicologia: Teoria e Pesquisa, v. 20, n. 2, p. 165-174, 2004.

PONCIANO, E. L. T.; FÉRES-CARNEIRO, T. Parent-Child Relationship in the Transition to Adulthood, Autonomy and Relativization of Hierarchy. Psicologia: 
Reflexão e Crítica, v. 27, n. 2, p. 388-397, 2014. Disponível em: < http://dx.doi.org/10.1590/1678-7153.201427220 >.doi: 10.1590/1678.7153.201427220

PONTE, J. P. Novas tecnologias na aula de Matemática. Educação e Matemática, v.34, p. 2-7, 1995.

OLIVEIRA, D. S. de. O uso do vídeo em EAD: desafios no processo de ensino aprendizagem. Revista Cesuca Virtual: Conhecimento sem fronteira, v. 1, n. 1, 2013.

RAMOS, M. R. V. O uso de tecnologias em sala de aula. Revista Eletrônica: LENPES-PIBID de Ciências Sociais-UEL, v. 11, n.2, p.13, 2012,

RIZZINI, I.; PEREIRA, L.; ZAMORA, M. H.; COELHO, A. F.; WINOGRAD, B.; CARVALHO, M. Adolescentes brasileiros, mídia e novas tecnologias. Revista Alceu, v. 6 , n. 11, p. 41-63, 2005.

VÁSQUEZ-CANO, E.; SEVILLANO, M.L. Dispositivos digitales móviles em educación. El aprendizage ubico. Madrid: Narcea, S.A. de Ediciones, 2015.

VISE, D. The google story. Strategic Direction, v. 23, n. 10, 2007 Disponível em: <http://dx.doi.org/10.1108/sd.2007.05623jae.001>. doi: $10.1108 / \mathrm{sd} .2007 .05623 \mathrm{jae} .001$

VON AHN, L. Duolingo: learn a language for free while helping to translate the web. In: Proceedings of the 2013 international conference on Intelligent user interfaces. ACM, p. 1-2, 2013. Disponível em: < http://dl.acm.org/citation.cfm?id=2449398>. doi: $10.1145 / 2449396.2449398$

YOUTUBE, Statistics, Disponível em:

<https://www.youtube.com/yt/press/statistics.html>, acessado 13 nov. 2016.

ANEXO I

Identificação

Nome (opcional):

Curso:

Série:

Este questionário tem como objetivo coletar dados em relação ao uso do celular no dia-a-dia das pessoas para o desenvolvimento do Projeto de Pesquisa Desenvolvimento de Aplicativos Educacionais de Química a ser realizado no Instituto Federal de Educação, Ciências e Tecnologia do Câmpus Uruaçu em parceria com a Universidade Federal de Goiás.

1) Você utiliza celular? $\mathrm{Na}$ tabela abaixo consta as principais atividades do uso do celular hoje em dia, avalie todas as atividades marcando um $(X)$ conforme a sua frequência de uso do aparelho para: 


\begin{tabular}{|l|l|l|l|l|}
\hline $\begin{array}{l}\text { Atender e fazer } \\
\text { ligações }\end{array}$ & Nunca usei & Muito pouco & Às vezes & Frequentemente \\
\hline $\begin{array}{l}\text { enviar mensagem via } \\
\text { sms }\end{array}$ & & & & \\
\hline tirar foto & & & & \\
\hline ouvir música & & & & \\
\hline redes socias & & & & \\
\hline acessar a internet & & & & \\
\hline jogar & & & & \\
\hline localizar endereços & & & & \\
\hline assistir filmes & & & & \\
\hline usar aplicativos & & & \\
\hline
\end{tabular}

2) Você possui aparelho celular? Qual a marca e modelo? (Exemplo Motorola- Moto G 3ํ Geração, Sansung -Galaxi S6)

3) Você utiliza ou já utilizou algum aplicativo do celular para auxiliar nos seus estudos? Qual (is)?

4)Porque o celular é importante para você? 